\title{
UN CURIOSO COLECCIONISTA DEL SIGLO XVII: DON MANUEL DE PORRAS
}

\author{
POR \\ MERCEDES AGULLÓ Y COBO
}

\begin{abstract}
El coleccionismo - afición casi exclusiva de Reyes en España- no ha tenido representantes entre personas que no pertenecieran a la alta nobleza, ni entre los propios artistas. En muchos casos lo que se ha venido llamando colecciones son sólo relación de bienes patrimoniales. Por ello, resulta más llamativo encontrar alguien que, sin pertenecer a una clase elevada ni ser artista, lograra reunir - aun a costa de grandes sacrificios que le llevaron al extremo de ser enterrado de limosna - una tan importante colección de obras de arte como el personaje objeto de este artículo: Manuel de Porras, quien contaba con un interesante y elevado (para un particular sin títulos) número de pinturas y esculturas, y un importantísimo número de dibujos y estampas, algunas valiosísimas y de alto precio. Desgraciadamente, aunque lo donó - como buen coleccionista, para evitar su dispersión - a los Trinitarios calzados de Madrid y al Oratorio de San Felipe Neri de Alcalá, nada de ello ha llegado a nuestros días.

Palabras clave: Coleccionismo. Manuel de Porras. Convento de Trinitarios de Madrid. Oratorio de San Felipe Neri de Alcalá.

Art collecting - an avocation almost exclusive to royalty in Spain - has not had representatives among those who did not belong to the high nobility, not even among artists themselves. In many cases, the word "collection" has been applied to what in reality were mere lists of patrimonial properties. For all of the above, it is especially noteworthy to encounter someone who neither belonged to an elevated class nor was a painter, but who managed to unite, at great personal sacrifice, an important art collection. Manuel de Porras owned interesting and a relatively large number of paintings, sculptures and prints, some of them extremely valuable. As a good collector, in order to avoid the dispersion of these works, he donated them to the Shod Trinitarians in Madrid and the Oratory of Saint Philip Neri in Alcalá, but unfortunately, in spite of his good intentions, nothing has survived.
\end{abstract}

Key words: Collecting. Manuel de Porras. Trinitarian Convent of Madrid. Oratory of Saint Philip Neri of Alcalá.

El coleccionismo - y específicamente el coleccionismo de obras de Arte - no ha sido ni es afición, dedicación ni ocupación primordial de los españoles. Salvemos de esta generalización las excepcionales excepciones que fueron algunos de nuestros Monarcas y otros casos aislados que sólo vienen a confirmar la regla. Incluso en la formación de las colecciones reales no se puede excluir, junto a la atracción por la belleza formal, elementos como la manifestación de un poder que se expresaba en la posesión. Los nobles y grandes señores, los funcionarios que ocupaban cargos de singular importancia siguieron el ejemplo real $y$, muchas veces 
por mimetismo y por espíritu de emulación, dieron pie a la creación de colecciones de Arte. No excluyamos tampoco que algunas de estas colecciones particulares se crean a veces de modo accidental partiendo de una inicial adehala con la que un artista «paga» el favor de una recomendación, de un encargo o incluso de una valoración en una tasación.

En muchos casos, las obras de arte se encargaban para vestir un palacio, como elemento decorativo y enriquecedor de una vivienda; se buscaba la «firma» que venía a destacar el nivel económico o social del poseedor de una obra. Tampoco se puede descartar que los Inventarios y las Tasaciones - hechas esencialmente con motivo de matrimonios, defunciones y particiones de bienes- den cuenta de fondos artísticos que erróneamente se han considerado colecciones cuando, en la mayoría de los casos, no son más que complemento del habitual «menaje de casa». ¿Cómo no iba a consignar una dama las joyas que constituían su dote?, ¿cómo no va a figurar en una relación de las posesiones de un platero, de un pintor, de un abridor de estampas, un número — nunca exagerado - de piezas de plata, de pintura o de estampas? Cuadros de tema religioso, bodegones, paisajes, son frecuentes en estos documentos notariales. Pero ¿debe considerarse coleccionista a su poseedor? Recordemos que la gran mayoría de las pinturas figura sin nombre de autor y que en casi ningún caso deja de consignarse el valor del marco, que en ocasiones supera al del lienzo.

Muchos ejemplos podríamos ofrecer que abonan estas afirmaciones. Incluso en los casos de Inventarios de bienes de artistas, son muy pocos en los que el número de lienzos firmados supera la media, limitándose la relación a sus propias obras, algunas de otros pintores — generalmente conservadas como recuerdo de su maestro o de un amigo- y, en el caso de las estampas y dibujos (tampoco abundantes en exceso), como materiales de trabajo y de enseñanza.

Se puede decir que hubo «coleccionadores», no coleccionistas, personas que reunían obras de arte sin criterio seleccionador, bien en respuesta a su gusto, al prestigio de un autor o a la valoración de la pieza. Si a todo ello añadimos la escasez de dinero - estamos en el siglo XVII- que hoy llamaríamos «cash», a la poca disponibilidad de medios dinerarios -manifiesta en hipotecas, préstamos, empeños, que alcanzaba incluso a la hacienda real- con que hacer realidad lo que podría ser el deseo de un coleccionista en ciernes, llegamos a la conclusión de que el número de auténticos coleccionistas se reduce a un muy pequeño número.

Todas estas consideraciones - que aplicamos especialmente a los siglos XVI-XVIII- se han prolongado en el tiempo hasta nuestros días, en que el slogan Invierta en Arte es justamente lo opuesto al principio que debe presidir la formación de una auténtica colección.

Por todo ello, nos ha resultado especialmente atractivo el personaje del que vamos a hablar: don Manuel de Porras, en quien el coleccionismo particular tiene un muy digno representante. No tuvo títulos, ni excesivos bienes, ni destacada posición social, ni ocupó puesto alguno - ni siquiera de importancia menor- en la enmarañada administración y gobernación del Reino que le abonasen en su afición por el Arte y, sin embargo, supo reunir a lo largo de toda su vida un muy interesante conjunto de obras que le hacen destacar en su tiempo.

Nacido hacia 1638 — con la habitual imprecisión, en documento de 1678 declaró que tenía cuarenta años poco más o menos - fue hijo de Domingo de Porres y de doña María de Quiñones y Porras; tuvo un hermano de nombre Francisco. No sabemos de sus estudios ni de su formación, ni en documento alguno consta ejerciese oficio u ocupase destino que exigiera título. Fue Mayordomo y apoderado del Convento de franciscanas de Santa Clara de Alcalá de Henares y a lo largo de su vida, de duración más o menos normal para su siglo — murió de sesenta y un años- le encontramos relacionado con la Cofradía del Hospital de Santa María la Rica de la misma ciudad, del Convento de la Trinidad Calzada de Madrid, del del Espíritu Santo de la Orden de Santiago de Salamanca, del de San Juan de la Penitencia de Toledo y muy especialmente con la Congregación de San Felipe Neri en sus establecimientos madrileño y alca-

AEA, LXXVI, 2003, 303, pp. 235 a 248 
laíno. Fue también administrador de unas Memorias pias para casar huérfanas, fundadas por Diego Ruiz Angelo y su mujer en el madrileño Monasterio de San Jerónimo, y administró judicialmente una casa en la calle de Santa Catalina la Vieja en nuestra Villa.

Como se ve, ninguna de estas ocupaciones están directamente relacionadas con el mundo del Arte, pero, según parece, le permitieron contar con ingresos suficientes para satisfacer sus afanes artísticos, sin olvidar que ese contacto con instituciones religiosas le permitiría estar también en relación con pintores, vendedores, compradores y tasadores que facilitaron el cumplimiento de su afición, puesto que la Iglesia fue, con mucho, el principal «cliente» del mundo del Arte de aquellos siglos.

Pero, ¿en qué momento, o por qué circunstancias empezó Manuel de Porras a interesarse por el Arte? Todo fueron hipótesis, hasta el hallazgo de un documento de 1671 en que figuran los nombres de los padres del personaje. En dicho documento ${ }^{1}$ consta que su madre respondía al nombre de doña María de Quiñones ${ }^{2}$, la cual fue testamentaria de Clara del Río, mujer en primeras nupcias de Domingo Simón Camilo (padre de Francisco, el pintor) y en segundas del famoso profesor de pintores Pedro de las Cuevas (padre del también pintor Eugenio de las Cuevas). Podemos incluso aventurar que perteneció a dicha familia de pintores y que, aunque fuera por poco tiempo y tal vez como mero aficionado, se inició en la pintura con Francisco Camilo y Eugenio de las Cuevas.

Vivió don Manuel de Porras en la calle de Atocha y posteriormente en las Cuatro Calles, donde murió. Hizo testamento el 6 de diciembre de 1698 y redactó una interesantísima Memoria de sus bienes el 21 de septiembre de 1699. Murió el 30 del mismo mes y año y, de acuerdo con sus disposiciones testamentarias, fue enterrado en el cementerio de la iglesia parroquial de San Sebastián (Doc. n. ${ }^{\circ}$ ).

No se conserva una documentación muy abundante sobre Porras, pero sí es lo suficientemente significativa para poder seguir su biografía y dejar establecido su amor por el coleccionismo de Arte. Apenas con veintitrés años, el 19 de septiembre de 1661, compró ocho obrillas de la almoneda de bienes del ya citado don Eugenio de las Cuevas, Pintor de su Majestad $^{3}$. Eran piezas de poco valor - no debía contar el comprador con muchos mediospero son ya expresión de una pasión que dominaría su vida. Compró «un retrato del Padre Cano, de la Orden de Santo Domingo», tasado en doce rs., por seis; por ocho rs. «dos caueças manchadas por el natural»; otra de San Cristóbal, por quince, que se había valorado en veinticuatro; «un túmulo antiguo, muy biejo», tasado en ocho y comprado en cuatro; un lienzo imprimado, que se había tasado en seis rs. y adquirió por cuatro; «tres bodegoncillos de pintura en tabla», por dos rs., y lo más interesante: «vnos papeles biejos tocantes a la pintura y dibujos y vnos colores y dos caxitas en que están metidos», que se habían tasado en doce rs. y Manuel compró por diez. Sólo fueron cuarenta y cinco rs. los gastados, pero era cantidad de relativa importancia para un mozo de veintitrés años, que no parecía contar con bienes de fortuna ni con oficio productivo. Destaquemos también que se trata de obras imprimadas, manchadas, borroncillos y que adquirió dibujos y colores y unos papeles «tocantes a la Pintura». ¿Adquirió tal vez alguna de las obrillas de su mano en las que trabajaba en el taller de Cuevas? ¿Intentó proseguir por el camino que suponemos había iniciado años antes? La rea-

\footnotetext{
' Carta de pago de don Manuel y don Francisco de Porras, hermanos y herederos de doña Ana María de Porras Quiñones, viuda de Domingo de Porras, sus padres, a favor de la iglesia de San Sebastián de cuantía de mil rs., que debían por escritura de obligación. Madrid, 3-X-1671. (AHP: Protocolo 10446).

${ }^{2}$ Por existir una María de Quiñones conocida, la mujer del impresor del Quijote, Juan de la Cuesta, fue identificada erróneamente en Documentos para la Historia de la Pintura Española I, Madrid, 1994, p. 30, al recoger el citado documento de Francisco Camilo.

${ }^{3}$ Agulló. Más noticias sobre pintores madrileños de los siglos xVI al xvIII, Madrid, 1981, pp. 66-67.
} 
lidad es que en 1661 compró tal vez los primeros dibujos de la que había de ser su importante colección.

Hemos recogido los datos relativos a precios de oferta y compra, porque precisamente esa obtención de rebaja en las pujas fue tema recurrente en la Memoria que luego comentaremos.

Mantuvo don Manuel su relación de amistad o de familia con Francisco Camilo. Fue, junto con el pintor Francisco Ignacio Ruiz de la Iglesia, testigo de la carta de pago del pintor a favor del Marqués de Loriana, como albacea y testamentario que fue Camilo de su hermano Eugenio de las Cuevas, el 25 de enero de $1663^{4}$ y lo fue también del testamento del pintor, dictado por su viuda doña Jerónima del Toral y Valdés en su nombre, el 20 de noviembre de $1673^{5}$. En aquel año, don Manuel ya era Administrador del Convento de Santa Ana de Alcalá.

Con fecha 7 de octubre de 1669 procedió a la tasación de las pinturas que formaban parte de los bienes de don Juan Reymundo de Aguayo, Nuncio del Consejo de la Santa Inquisición ${ }^{6}$. En ella figura don Manuel como «del Arte de pintor», calificándosele también de pintor en documento de 2 de enero de 1678: la valoración de las pinturas que poseía la viuda del Aposentador de su Majestad don Antonio Cerdeño, llamada doña Petronila Rodón y Monzón ?

El 3 de octubre de 1671, fallecidos sus padres, pagó junto con su hermano Francisco mil rs. a la iglesia parroquial de San Sebastián de Madrid, cantidad que adeudaban los difuntos por una escritura de obligación ${ }^{8}$. En años sucesivos prosiguió con sus actividades de Mayordomo del Convento alcalaíno de Santa Clara y efectuó diversos pagos y transacciones entre Conventos, Cofradías y particulares ${ }^{9}$.

Carecemos de noticias de Manuel de Porras entre su tasación de 1678 y el año de 1685, aunque no debió permanecer ajeno al mundo del Arte, ya que el 28 de junio de aquel último año, doña Lucía Barragán, viuda del pintor Francisco de Solís (quien había fallecido el año anterior), le otorgó poder no sólo para cobrar «de todas y cualesquier personas, de qualquier estado y calidad que sean», cuanto se le adeudase, sino también para otorgar las correspondientes «cartas de pago, finiquitos, cesiones, lastos... y para que pueda hacer pública almoneda y venda en ella todos los vienes muebles que tengo y me pertenezen en los prezios que quisiere», y para ocuparse igualmente de la administración de unas casas que la viuda de Solís tenía junto al Hospital madrileño de San Andrés (Doc. n. ${ }^{\circ}$ 2).

Mucha y muy buena relación debió tener nuestro personaje con el fallecido pintor, mucha la confianza que le inspiraba a su viuda y muy buena debía ser la reputación de don Manuel como conocedor de la Pintura y su mundo, cuando doña Lucía Barragán puso en manos de don Manuel toda su hacienda y la de su difunto marido.

Otra laguna documental de diez años nos lleva hasta 1695, año en el que el 21 de enero aún cobró cierta cantidad de maravedíes en nombre de una religiosa de Santa Clara de Alca-

\footnotetext{
${ }^{4}$ Agulló, Más noticias, pp. 40-41.

${ }^{5}$ Agulló, Más noticias, p. 45.

${ }^{6}$ AHP: Protocolo 10098, fols. 126-128. Don Juan Raymundo o Raimundo de Aguayo y Valdés está documentalmente relacionado con Camilo: en 1669 parte de la dote de su hija Teresa Luisa, al contraer matrimonio con el médico Rodrigo Pérez de Vergara, estaba en su poder y fue testamentario de don Eugenio de las Cuevas en 1661 (Agulló, Más noticias, p. 44 y 46). No olvidemos tampoco que la mujer de Camilo se llamaba doña Jerónima Toral y Valdés.

${ }^{7}$ AHP: Protocolo 9205, fols. 181v-182.

8 Véase: Nota 1.

${ }^{9}$ El 17 de Julio de 1673, con poder de la Abadesa y Discretas del Convento de Santa Clara de Alcalá, cobró doscientos dcs. vn. de los réditos de un censo, de mano de don Diego de Alcocer y Velasco (AHP: Protocolo 11600, fol. 503). El 8 de enero de 1677 y haciendo uso del mismo poder, recibió ciento noventa rs. veinte mrs. de un censo impuesto sobre unas casas que estaban junto al madrileño Hospital de Santa Catalina de los Donados, de mano de don Antonio Díaz de Aguilar (AHP: Protocolo 11033, fol. 11). El 12 de diciembre del mismo año, en nombre del Padre Fray Francisco de Santa María, Prior del Convento de San Jerónimo de Madrid, Patrón de las Memorias fundadas por Diego Ruiz Angelo y doña Isabel de Herrera, su mujer, recibió del doctor don Lope de Ribera novecientos rs. vn. del alquiler de una casa en la calle de la Cruz (AHP: Protocolo 11033, fol. 765).
}

AEA, LXXVI, 2003, 303, pp. 235 a 248 
lá ${ }^{10}$, y el 24 de marzo declaró que había cedido su cargo de Mayordomo — que ejercía por poder del Convento de 9 de abril de 1673 - al vecino de Segovia don Tomás Ramos Plaza ${ }^{11}$.

Redactó don Manuel de Porras su testamento ${ }^{12}$ el 3 de octubre de 1698, como hemos dicho. En él, y tras la fórmula habitual por la que firmemente declaró su fe, encomendó su alma a Dios y ordenó que le amortajasen con hábito de San Francisco aunque no consta, o no lo indica, que fuera de la Tercera Orden, y que le enterrasen - como se hizo- en el cementerio de la iglesia parroquial de San Sebastián.

Detallada y minuciosamente fue dando cuenta el otorgante de sus deudas y deudores: debía unos cientos de reales del alquiler de la casa en que había vivido en la calle de Atocha antes de trasladarse a aquella en que murió en las Cuatro Calles; le adeudaba don Nicolás Rubio, caballero de la orden de Alcántara y Regidor de Madrid (a quien había cedido unas cartas de pago confiando «en la gran mano que los Regidores tienen con los Tesoreros de la Villa»), cien dcs. vn. de una enrevesada cuenta, dinero que pertenecía a una religiosa del Convento del Espíritu Santo de la Orden de Santiago en Salamanca; le debía otros veinte rs. el médico don Andrés de Talaya de Contreras del alquiler de una vivienda en la calle de la Cruz, a quien no se le pudieron embargar los libros que tenía, por cuando los de los médicos «mientras que viuen, no se podían vender», aunque la cantidad le fue abonada a la muerte del galeno por su testamentario, etc., etc.

Se relata también en el documento notarial su intervención en la venta de una Custodia de bronce dorada y piedras de adorno, tasada en su momento en mil dcs., en nombre de doña Jerónima López del Prior y su heredera, doña María Serrano y Puga, religiosa en el Convento toledano de San Juan de la Penitencia; actuó don Manuel como testamentario de doña Jerónima y en la venta - también enrevesada y llena de vicisitudes - intervino el famoso platero madrileño Manuel de Zurita.

No olvidó el encargo de algunas misas por su alma: ciento cincuenta (número no excesivo para su época) a tres rs. de limosna cada una. Y dejó por sus testamentarios a cuatro sacerdotes de la Congregación de San Felipe Neri de Madrid: don Pedro Luzera, don Dionisio de Paredes y don Julián Sánchez, y al Prepósito de la misma Congregación de Alcalá de Henares. Ya en ese testamento se habla de la Memoria que dejaría y que debió redactar entre esta fecha y el 21 de septiembre del año siguiente, que es la que lleva el documento (Doc. n. ${ }^{\circ} 3$ ).

Pasamos a comentarla. Bajo el epígrafe al margen «Pinturas mandadas a San Phelipe Neri de Alcalá» expresa don Manuel las razones que le mueven a donarlas a la citada Congregación, en vista sobre todo a impedir su dispersión, «por quanto - dice - tengo bastantes esperiencias de lo que en estos casos suele suceder en las personas que no entienden el primor del Arte, de que llaman quien lo entienda para que lo tasse, y los tales tasadores, como lleban la mira a conprarlo, tasan estas cosas en precios ynfimos y demás de ello quieren que les agan baxa y consiguen llebarse en quatro lo que bale ciento y que el testamentario o heredero que lo benden no sauen si lo pagan bien o no, por no entenderlo, y redunda en menoscauo de los vienes».

Realmente el párrafo parece un autorretrato de don Manuel. Si recordamos el primer documentos que de él conocemos - la almoneda de bienes de Eugenio de las Cuevas en 1661Porras adquirió entonces el retrato del Padre Cano en seis rs. cuando estaba tasado en doce, la

\footnotetext{
${ }^{10}$ AHP: Protocolo 10253, fols. 1-2.

$"$ AHP: Protocolo 10253, fols. 491-494.

${ }^{12}$ En el extenso documento hace hincapié el testador del rigor con que desempeñó sus tareas de administrador. De sus declaraciones se desprende que tuvo cierta familiaridad con personas de algún relieve de la Villa y Corte, así como su buena relación de vecindad tanto con los Trinitarios de la calle de Atocha como con el librero Juan de Valdés, establecido en la misma calle, con los Patronos de algunas de las Memorias pías que administraba y con las religiosas de los diversos Conventos de cuyas finanzas se ocupaba. Destaca, no obstante, en el documento, que no haya referencia alguna a sus bienes muebles o a su ajuar de casa, así como que no se cite en él ni a familiares ni a criados.
} 
cabeza de San Cristóbal en quince, tasada en veinticuatro e incluso obtuvo una rebaja de dos rs. al comprar pinturas y dibujos. ¡Bien conocía el paño nuestro tasador-comprador!

No fueron sólo lienzos lo que dejó al Oratorio de Alcalá: en la Memoria figuran también unos «escaparates» (urnas o armarios con puertas de vidrio en que se conservaban imágenes o escenas de bulto): Nuestra Señora, el Niño y San Juanito con ángeles; San Eustaquio a quien se aparece el ciervo con un Cristo entre las astas; una urna de carey con un Nacimiento. Les donó también dos tallas de Niño (probablemente Niño Jesús y San Juanito, de los llamados de Nápoles) y un numeroso conjunto de reliquias en sus correspondientes relicarios.

Constan en la Memoria veintidós pinturas; sólo tres de ellas con nombre de autor; una cabeza de San Pedro, de Juan Carreño de Miranda; un retrato (suponemos que de hombre) «con un sonbrero puesto», de José Antolínez, y una cabeza de mujer de medio perfil, «de mano de Matheo Carreño [sic], echa por su muger», es decir, tomándola como modelo, que nos acerca el recuerdo del retrato de doña Juana Pacheco, que pintó Velázquez y que en el caso que nos ocupa — por la unión errónea de nombre y apellido- no sabemos si era de Mateo Cerezo o del citado Juan Carreño.

Contaba con una pintura de tema del Antiguo Testamento; el hallazgo del niño Moisés en el Nilo por la hija del Faraón. Otra del Nuevo: Cristo y el centurión. De tema religioso mariano dos Sagradas Familias —una de ellas con San Juan-, una Virgen con el Niño y una Nuestra Señora de la Concepción «yncada de rodillas, rodeada de muchos ángeles», pudiéndose tal vez incluir en este apartado el país con «vn ángel cojiendo guindas de un árbol», que puede ser un fragmento de el descanso en una Huida a Egipto y nos trae a la memoria los lienzos de este tema de Francisco Rizzi y de José Moreno, aunque en estos dos cuadros el árbol es una palmera y evidentemente los frutos son dátiles. Entre los Santos, aparte de la cabeza de San Pedro, de Carreño, los martirios de San Sebastián (en el momento en que le ataban a un árbol) y San Hermenegildo, aunque éste puede incluirse en la temática de Historia de España, por cuanto aparece sobre un tablado y con multitud de figuras asistentes al espectáculo, obra de un pintor que seguramente había asistido a algún Auto de Fe.

Pero el conjunto más llamativo de la colección de don Manuel de Porras lo constituyen las cinco pinturas de tema mitológico y profano: una bacanal, definida en la Memoria como «un país con diferentes figuras que están en un festexo que se llama bacanaria, con tres muchachos en el ayre tirando flechas»; un «Baño de Diana» con Acteón, perros y otras figuras bañándose; un «Rapto de Europa»; una «Mujer mirándose a un espejo que sostiene un muchacho» (que evoca inevitablemente la Venus de Velázquez o algunos desnudos de Tiziano y Veronés) y el «Niño montado en un delfín».

Se completa el lote pictórico que legaba a los filipenses alcalainos con lo que denomina «país con vna fuente enmedio, en que tiene por remate un muchacho echando agua por vna basija» (representación cercana a las varias representaciones de las fuentes de Aranjuez o incluso a la famosa de Martínez del Mazo); otro país «sin figuras y terazos»; un niño con un perro y dos miniaturas femeninas (óvalos de dos o tres dedos de alto) —una de ellas la Reina Doña Isabel de Borbón- que conservaba en un escritorio.

Todas ellas — veintidós como hemos dicho- «de autores grandes», como informa el poseedor. Por todos los medios intentó Porras que el conjunto permaneciese en manos de aquellos a quienes se los donaba. Aunque los destinatarios eran los religiosos filipenses, cuyo Oratorio alcalaíno se estaba concluyendo, mientras la obra se perfeccionaba, todas ellas debían servir para adorno de la Capilla de Jesús Nazareno del Convento de Trinitarios descalzos de Madrid, aunque no podrían venderlas ni entregárselas a los filipenses de Alcalá hasta que su iglesia estuviera acabada.

Otra de las disposiciones de la Memoria — junto a la ya expuesta sobre la compra de obras

AEA, LXXVI, 2003, 303, pp. 235 a 248 
de arte a precios bajos aprovechando la ignorancia de los vendedores - en que se manifiesta el conocimiento que nuestro coleccionista tenía de las malas prácticas de los pintores, dice expresamente que ninguna de las pinturas donadas podrían «prestarlas a persona alguna ni a pintores para que las copien, por el riesgo que tienen de que las maltratan y suelen trocar o quedar con ellas y echarlas a perder con los papeles aceitosos y colores que ponen enzima de los orixinales, y al limpiarlo con la miga de pan quitan el balor y la grasilla que tiene la pintura, quitándoles el balor por este camino». ¡Cuántas pinturas no habrán llegado a nuestros días víctimas de esas malas artes de copistas y restauradores! Lienzos resecos que han perdido la pátina — «grasilla» la llama nuestro don Manuel— a manos de tanto incompetente restaurador, afanoso de devolver un hipotético aspecto original a una obra suavemente oscurecida por el paso del tiempo. Empleo de miga de pan y aun de cebolla en la limpieza, uso de papeles de copia..., sin olvidar los «cambiazos» y las «pérdidas»...

Pero si de importante puede calificarse para un particular contar con no menos de veintidós lienzos «todos de autores grandes», de excepcional ha de considerarse la de dibujos, al menos por su número, ya que en su Memoria no se hace referencia a sus autores. Hace constar en ella que tenía «quatro libros grandes, o los que fueren, y los demás libros en que estubieren pegados, de dibujos de mano de ynsignes pintores antiguos y modernos y de diferentes artífizes», así como otros «ya sea de pluma y de lápiz o aguadas», que conservaba sueltos entre las hojas de los libros de su biblioteca, otros atados «metidos entre pargaminos» y otros montados con sus vidrieras y molduras o en bastidores. Eran piezas por las que el donador muestra especial cariño, «los quales balen - dice - y me han costado muchísimos ducados y ser alajas muy esquisitas que e adquirido y conprado en el distrito de muchos años». Este conjunto sí era obra de un auténtico coleccionista y resulta tanto más excepcional por cuanto apenas unos cientos de dibujos de nuestros más excelsos pintores se conservan y sólo un limitadísimo número de artistas (Solís, Ezquerra, Meléndez...) se interesaron por su conservación. ¡Lástima que Porras no hiciera ni siquiera mención de alguno de ellos!

Quiso también que este excepcional lote - que permite calificar a nuestro personaje de verdadero «connoisseur» y enterado e interesado por el Arte - se mantuviera sin disgregarse y, confiando en la excomunión que pesaba sobre quienes osaran sacar cosa alguna de la que él llama «librería grande» - suponemos que la de la Comunidad- del Convento de la Trinidad calzada de la Corte, donó el espléndido conjunto a los religiosos trinitarios. Justifica su preocupación «por el riesgo que tiene de que se estrabien algunos y los vrten, porque estas cosas son de mucha golosina para artífizes y pintores, que yo los e juntado por la grande afición que e tenido a este género de cosas y e gastado mucha hazienda».

Serían también los trinitarios los beneficiarios de «diferentes cantidades de enboltorios atados y libros y rollos de estanpas de papel, vnas forradas en lienzo y otras sin forrar (...) que tanbién balen y me an costado muchos ducados, por ser de gran balor y estimazión y de autores de diferentes naçiones y Escuelas, como es de Benecia, Flandes, Françia y otras partes». Muchas debían ser aunque no las especifica. Sólo, por su importancia y valor - le habían costado no menos de dieciocho doblones de a dos escudos de oro- menciona «siete estanpas de papel forradas en lienzo, de cosa de bara y media de largo las zinco, y las dos algo más pequeñas; que las cinco de ellas son de la Ystoria y azañas de el Enperador Alexandro Magno, y las otras dos de las Azañas de el Enperador Constantino Magno». Se trata, probablemente, en el primer caso, de las cinco estampas grabadas por Audran, según pinturas de Lebrun, y en la serie de Constantino, de las otras dos debidas al mismo pintor y grabador, hechas en 1666, piezas de extraordinaria calidad y excepcional tamaño (van de los $155 \times 70 \mathrm{cms}$. a los $95 \times 70 \mathrm{cms}$. en las de menor formato) ${ }^{13}$.

\footnotetext{
${ }^{13}$ Debo y agradezco estos datos a mi buena amiga Elena Santiago.
} 
Debieron ser algunas de las últimas adquisiciones de don Manuel, que incluso determina a quien se las compró: a don Francisco Martínez, que vivía en la calle de Preciados, y que es seguramente el mercader de libros así llamado, establecido en la Puerta del Sol, de donde arranca la citada calle, esquina a la de los Cofreros y cuya actividad se prolongó por lo menos hasta 1685.

La consideración del valor e importancia de estas siete estampas hace insistir al donador en sus reflexiones sobre sus propias experiencias acerca «de los fraudes que se an cometido y menoscauo del balor que an tenido las alajas que se an bendido en diferentes almonedas y mayormente estos géneros de cosas que son codiciosas para artífizes, y éstas las tasan en precios ynfimos con el ánimo de conprarlas muy baratas, siendo así que, como llebo dicho, me an costado cantidades muy escesibas de doblones y reales de a ocho».

Es conocido, y cada día se presta mayor atención, al empleo de estampas por grandes pintores, que las utilizaban como «modelos» en sus composiciones. Bien lo sabía ya Porras que las califica muy acertadamente de «codiciosas para artífizes».

En cuanto a los libros impresos y manuscritos que figuraban en su biblioteca, y de los que sólo habla genéricamente, eran también para el citado Oratorio de San Felipe Neri de Alcalá, su universal heredero ${ }^{14}$.

Debemos aún mencionar tres piezas «de bulto» que, de ser originales como el donante afirma, serían realmente excepcionales: un gladiador, escultura «firmada en lengua griega, del autor Glayzo», es decir del famoso estatuario del siglo Iv antes de Cristo, Glauco, a quien se atribuye el invento de soldar los metales; otra en bronce «que hace vn mobimiento que carga la cabeza contra el pecho, y la otra es de metal, en pie, llamada el Antiño», es decir, un Antinoo.

En el coleccionismo del siglo XVII es excepción ese decidido interés por el mundo clásico que manifiesta don Manuel, un particular sin relieve social, que se atrevió a tener tres desnudos masculinos (uno de ellos nada menos que del hermoso efebo amante de Adriano), que murió soltero (solterón, más bien, ya que tenía más de sesenta años cuando murió), que coleccionaba óleos de tema mitológico, en los que destacan los desnudos, y que sólo contaba - aparte de la cabeza de San Pedro, de Carreño, conservada probablemente por la firma - con un San Sebastián y un martirio de San Hermenegildo dentro del tema hagiográfico, que probablemente tendrían poca ropa en el momento de sus respectivos martirios...

Pasemos ahora a hablar de los beneficiarios de sus tesoros: los Tinitarios descalzos de Madrid y muy especialmente el Oratorio de San Felipe Neri de Alcalá de Henares.

La relación con los primeros le vino con toda probabilidad de la proximidad de su habitación, ya que vivió muchos años en la calle de Atocha, donde estaba el Convento de la Trinidad. En cuanto al Oratorio alcalaíno, no hay que olvidar que Porras, ya desde 1671 por lo menos, llevaba los negocios de las franciscanas de Santa Clara de aquella ciudad y estaba relacionado con otros conventos y Cofradías de la misma, amén de que el Oratorio filipense de Madrid - de donde salieron los Padres fundadores del de Alcalá- estuvo establecido desde 1660 en la Plazuela del Angel. De este emplazamiento pasó, ya en la segunda mitad del siglo xviII, a la Plazuela de Herradores, ocupando la iglesia y demás dependencias que constituían el Convento de los jesuitas expulsados, que llevaba la advocación de San Francisco de Borja.

Como hemos dicho, don Manuel de Porras dejó por sus testamentarios a cuatro Padres oratonianos; tres de la Congregación de Madrid — don Pedro Luzera, don Dionisio de Paredes y don Julián Sánchez- y uno de Alcalá, el Prepósito de su Oratorio recién fundado.

Del Oratorio alcalaíno escribió Angel Alba ${ }^{15}$ un extenso artículo en el que nos proporciona, además de una importante información documental, una amplísima bibliografía de la ciu-

\footnotetext{
${ }^{14}$ El Oratorio posee «una magnífica biblioteca y sus libros tienen un gran valor bibliográfico», noticia que figura en la Guía Turística de Julián Gómez y que recoge Angel Alba en el artículo que comentaremos más adelante.

${ }^{15}$ El Oratorio de San Felipe Neri de Alcalá de Henares (1694-1729), (AIEM, Tomo XIV, 1977, pp. 123-196).
} 
dad del Henares y específicamente del Oratorio. Fundado en 1694 por don Martín de Bonilla y Echevarría, canónigo de la Catedral de Avila y Obispo electo de Ceuta, entre otros títulos, fue su modelo más cercano el Oratorio madrileño y fue precisamente el Padre Dionisio de Paredes - uno de los testamentarios de don Manuel- «el más directamente interesado en la fundación» ${ }^{16}$ y el Padre Luzera ${ }^{17}$ —otro de los albaceas de Porras- quienes compraron los terrenos para el establecimiento de Alcalá, pudiendo considerarse ambos los verdaderos fundadores de la Congregación alcalaína. Teniendo en cuenta la fecha del testamento de Porras (1698), el Prepósito de Alcalá — cuarto de sus testamentarios- era el Padre Francisco Burgalés, figura destacada entre los Sacerdotes congregantes.

El doctor Dionisio de Paredes fue el octavo de los hijos de que tenemos conocimiento del impresor madrileño Julián de Paredes y su mujer doña María Hidalgo y fue bautizado en la iglesia madrileña de Santa Cruz el 16 de mayo de 1622 (Doc. n. ${ }^{\circ}$ 4). En aquella fecha su padre estaba establecido en la Plazuela del Angel, donde dos años antes había fundado el Padre don Diego Liñán el Oratorio de San Felipe Neri. El 10 de junio de 1692, con el Padre Luzera, fue testamentario de su madre doña María Hidalgo, perteneciendo ya ambos albaceas al Oratorio filipense ${ }^{18}$.

Se dijo Misa en el primer Oratorio provisional alcalaíno el 5 de diciembre de 1694, iniciándose las obras de otro «más grande y capaz» cuatro días más tarde. Este segundo templo se bendijo el 1 de marzo del siguiente año y se mantuvo hasta que el 4 o el $14^{19}$ de abril de 1698 se acordó hacer otra iglesia más acorde con los fines de la Congregación, obra que debió quedar terminada hacia 1704. Muerto el fundador Padre Bonilla, el 5 de diciembre de 1697, en Madrid, se trasladaron sus restos a Alcalá y se puso epitafio sobre su tumba en 1705. No prolongaremos más allá la historia del Oratorio, ya que son los años 1698-1699 los que nos interesan para la biografía de don Manuel de Porras.

En su testamento dejó el otorgante por su «vnica y vniuersal heredera» a la Casa y Congregación de San Felipe Neri de Alcalá. La fecha del documento, 6 de diciembre de 1698, se corresponde exactamente con la de la decisión de los filipenses de fabricar una nueva iglesia. Pero en ningún documento se hace referencia a nuestro coleccionista, ni en años sucesivos, muerto ya don Manuel, se recuerda para nada la generosa donación detallada en su Memoria de 21 de septiembre de 1699, ni hay noticia de que su colección de lienzos, escaparates y relicarios, más los libros que integraban su biblioteca, hubieran pasado a formar parte del patrimonio del Oratorio de Alcalá.

Parece lógico que su nombre no conste entre los de aquellos que con su dinero contribuyeron al establecimiento de Alcalá o a la construcción de la iglesia nueva, ya que en su testamento don Manuel ordenó que le llevasen a enterrar como a pobre en las andas de la Cofradía de la Misericordia - cuya finalidad era, precisamente, la de sepultar a los que carecían de bienes para ello-y que portasen su cuerpo «quatro esportilleros o pobres», lo que parece indicar que carecía de dinero en efectivo y que sus bienes muebles no alcanzaban para más, excepción hecha de la citada colección artística. Añadamos que en dicho testamento no se hace referencia a los más elementales objetos que constituyen un ajuar de casa: cama, ropa, trastos de cocina..., lo que nos hace suponer que eran muy escasos y carecían de todo valor. Sin embargo, no tiene justificación y resulta incomprensible que ninguna de las obras que dejó al Oratorio

\footnotetext{
${ }^{16}$ Art. cit., p. 145.

${ }^{17}$ Figura siempre así en la documentación que yo he consultado, pero Alba me indica que su verdadero apellido era Llusera.

${ }^{18}$ Los documentos sobre la familia de impresores madrileños de apellido Paredes están recogidos en mi Tésis inédita $L a$ Imprenta y el comercio de libros en Madrid (siglos XVI-XVIII). Madrid, 1991, 2 vols. de 500 y 1012 páginas.

${ }^{19}$ Con ambas fechas figura en el citado artículo de Alba, p. 150 y Nota 57.
} 
pasase a ornamentar la iglesia o dependencias de los religiosos. En ningún papel, en ninguna publicación se menciona al donador o a lo donado ${ }^{20}$. Se habla de los regalos de los padres Bonilla, Paredes y Luzera, de las obras de Arte que poseía e incluso de las que hoy conserva el Oratorio, pero entre ellas no se cita ni el San Pedro de Carreño, ni la Inmaculada rodeada de ángeles, ni las dos Sagradas Familias, ni las esculturas del Niño Jesús y San Juan, ni los relicarios, tan valorados en su época y que prestigiaban a la iglesia en que se exhibían, etc., etc. ${ }^{21}$.

Hay constancia de la urgencia con que el Padre Paredes, como testamentario de don Manuel, protocolizó la Memoria en que constaba la donación, al día siguiente de su fallecimiento, el 1 de octubre de $1699^{22}$, pero parece que el albacea olvidó inmediatamente las disposiciones del difunto para que las obras no se vendiesen ni enajenasen. Paredes vendió la Bacanaria (la descrita como «un país con diferentes figuras que están en un festexo, que se llama bacanaria, con tres muchachos en el ayre tirando flechas»), de $62,7 \mathrm{~cm}$. de ancho, cuya procedencia por muerte de Porras se conoce en Alcalá, y la «pintura de Europa» (que figura en la Memoria como «Vna Europa, de tres quartas de ancho, poco más, sentada sobre vn toro, en un mar, con vnos muchachos en el ayre tirando flechas, con moldura parda»), así como la «pintura de poco más de quarta, de vna caueza de vna muger puesta a medio perfil, de mano de Matheo Carreño [sic] echa por su muger». Las tres fueron vendidas a un don Benito Escalante en 1705: la Bacanal por doscientos setenta rs. vn., el Rapto de Europa por doscientos cuarenta y el retrato de la mujer de Mateo Cerezo por cien ${ }^{23}$. Parece razonable que el Padre Paredes se desprendiera de las dos primeras pinturas, las cuales por su tema difícilmente encajaban en una Congregación religiosa; lo es menos la venta de la pintura de Cerezo y, desde luego, carece de toda explicación que no haya noticia en el Oratorio de Alcalá del resto de las obras.

Más desalentadora, si cabe, ha sido la búsqueda de los numerosos dibujos y las incontables estampas que reunió don Manuel a lo largo de toda su vida — desde la adquisición de aquellos «papeles biejos tocantes a la pintura y dibujos» de la almoneda de bienes de don Eugenio de las Cuevas en 1661- de los que dejó por beneficiarios a los Trinitarios descalzos del Convento de Madrid. No existe noticia de la recepción del legado por la Congregación trinitaria madrileña, ni Inventario en que se haya recogido el voluminoso conjunto de libros con dibujos pegados en sus hojas, ni de los intercalados en obras impresas, ni de los «enboltorios atados y libros y rollos de estanpas de papel» venecianas, flamencas, francesas y de otros países, que con tanta atención y a tan subido precio adquirió Porras.

¿Olvidó también en este caso el Padre Paredes las recomendaciones del donante? ¿No llegaron a entrar en poder de los trinitarios los dibujos y estampas legados? El número de piezas

\footnotetext{
${ }^{20}$ Art. cit., Bibliografía y Apéndice, pp. 177-196.

${ }^{21}$ Las noticias sobre las obras de arte conservadas en el Oratorio de Alcalá se han venido repitiendo con variantes y diversas atribuciones. Haremos especial mención a la Guía editada por el Patronato Nacional de Turismo en 1931, que escribió don Elías Tormo, el cual da como existentes en la iglesia de San Felipe Neri un San José de Palomino, dos ángeles de Claudio Coello, y una Inmaculada de un imitador de Alonso Cano, y en la Casa, un San Bruno de Carreño y una Inmaculada firmada por Pereda en 1637, más otras pinturas de Ardemans, Donoso, etc. De la Inmaculada de Pereda habla también Julián Gómez, en su citada Guía turística y Jorge Bela Durán en Alcalá de Henares en su bolsillo, editada en 1966. F. Garcés en Alcalá de Henares y su Partido, de 1970-72, hace referencia a una pequeña Inmaculada de Cano o de su escuela, mientras que el San Bruno de Carreño afirma que don Diego Angulo se lo atribuía a Zurbarán. Citaremos también a Quintano Ripollés, autor de una Historia de Alcalá de Henares editada en 1973, en la cual afirma que en el Oratorio se conservaban en aquella fecha una Concepción de Pereda, hijo, el San José de Palomino, y atribuye el San Bruno de Carreño a Carducho. Todos estos datos proceden del citado artículo de Angel Alba.

${ }^{22}$ Ante el escribano Juan Hernández de Madrid, el «doctor don Dionisio de Paredes, presuítero del Oratorio de la Congregación de San Phelipe Neri de esta Corte, testamentario de don Manuel de Porras» declaró que había hallado la Memoria citada en el testamento del difunto. Por auto se le ordenó que la pasase a escritura pública y se tuviese por parte del mismo. Se transcribió íntegra (AHP: Protocolo 14276, fols. 744-746). En este Protocolo no hay más noticias sobre los bienes de don Manuel de Porras.

${ }^{23}$ Debo a la amabilidad de Angel Alba estas noticias, que certifican que entraron en el Oratorio, por lo menos, algunas de las pinturas propiedad de Porras.
}

AEA, LXXVI, 2003, 303, pp. 235 a 248 
y su valor no parecen justificar que los testamentarios las vendiesen para cumplir las limitadísimas mandas y las pocas misas que don Manuel dejó ordenadas en su testamento. Los dos ducados abonados a la parroquia de San Sebastián, los pocos maravedíes que se darían a los esportilleros que llevaron al difunto y a los dos pobres que le alumbraron con sus hachas, el pago al Sacerdote que acompañó al entierro, la limosna a la Cofradía de la Misericordia, más el precio de las ciento cincuenta misas encargadas y las pequeñas deudas declaradas en sus últimas disposiciones testamentarias, no pudieron ser justificación para desprenderse de tan importante conjunto artístico. Pero lamentablemente, no cabe ninguna otra explicación.

Quede por lo menos el recuerdo de un hombre que dedicó todos sus esfuerzos y, considerando lo logrado, toda su vida al Arte; que intentó por todos los medios que un patrimonio conseguido probablemente a costa de muchas renunciaciones incluso en el ámbito de su vida cotidiana, se mantuviese reunido en manos de quienes consideró podrían ser sus fieles conservadores. Y que conoció en sus entresijos un mundillo —el de los comerciantes de obras artísticas, copistas y restauradores - que parece haber llegado a nuestros días sin notables cambios.

\section{DOCUMENTOS}

\section{Documento n. ${ }^{\circ}$ :}

«Don Manuel de Porres, soltero, de hedad de çinquenta años, hixo de Domingo de Porres y de María Quiñones y Porres, (difuntos). Viuia en las Quatro Calles, en casas de Joseph Martínez de Robles. Murió en treinta de septiembre de mill seiscientos y nouenta y nueue años. Reciuió los Santos Sacramentos. Dexó mill, digo ciento y zinquenta, misas de limosna de a tres rs. Y por una memoria que dexó firmada de su mano, que se refiere en dicho testamento, dexó otras cinquenta misas de la misma limosna. Y por sus testamentarios a el Padre don Pedro Luzera, el Padre don Dionisio de Paredes y a el Padre don Julián Sánchez, de la Congregación de San Phelipe Neri de la ciudad de Alcalá de Henares. Enterróse en público en el cementerio de esta iglesia parroquial de San Seuastián por dexarlo así mandado por dicho testamento. Y dio de fábrica dos ducados». (LESS, 30-IX-1699).

Se afirma en esta partida que murió a los cincuenta años. Murió en realidad en torno a los sesenta y uno. El error debió cometerlo el sacristán o archivero de San Sebastián. No pudo nacer don Manuel en 1649 ya que en 1661 - año en que tendría doce- compró las primeras obras de la que sería su colección. Debo la transcripción a D. Angel Aterido.

\section{Documento n. ${ }^{\circ}$ :}

«Poder para cobrar. Por doña Luzía Barragán a don Manuel de Porras. En 28 de junio»

«Sépase cómo yo, doña Luzía Barragán, vezina de esta Villa de Madrid, biuda de don Francisco de Solís = Otorgo que doi todo mi poder cumplido... a don Manuel de Porras, vezino de ella, para que en mi nombre y representando mi propia persona y derecho, así por mí como por heredera del dicho mi marido, pida, aya, reziua y cobre judizial o extrajudizialmente de todas y qualesquier personas de qualesquier estado y calidad que sean, todas las cantidades de maravedíes que me deuan y deuieren en virtud de escripturas, papeles $\mathrm{v}$ otras qualesquier que sean, y de ellas dé cartas de pago, finiquitos, cesiones y lastos con los demás recados que le sean pedidos... Y para que pueda haçer pública almoneda y venda en ella todos lo vienes muebles que tengo y me pertenezen, en los prezios que quisiere, y cobre los alquileres de vnas casas que tengo mías propias al Hospital de San Andrés y las arriende, sin que pueda venderlas, hipotecarlas mi enejarlas [sic por enajenarlas]. Y si sobre todo lo referido o qualquier cosa o parte de ello que se me pueda ofrezer fuere nezesario parezer en juizio, lo pueda hazer», así como para hacer toda clase de diligencias que fueran necesarias. Hipotecó para ello todos sus bienes. Testigos: «Pedro López de Montaluo, don Joseph de Auendaño y Phelipe Antonio de Arze, residentes es esta Corte». Firma: «doña luçia barragan». Madrid, 28-VI-1685. (AHP: Protocolo 12553, fol. 314).

\section{Documento n. ${ }^{\circ}$ 3:}

«Digo yo, don Manuel de Porres, que por quanto en seis de diziembre del año pasado de mill seiscientos y nouenta y ocho otorgué mi testamento abierto ante Juan Bauptista de Siuera, escriuano de Su Magestad, y 
en él prebengo que vna memoria que se allará en mi poder, escrita de mi mano o de mano agena y firmadas las partidas de mi mano, se cumpla, guarde y execute lo contenido en ella como pareçe del dicho testamento. Y poniéndolo en execuzión hago la dicha memoria en la forma y manera siguiente:

$\ll \mathrm{D}$. Andrés

Talaya» En dicho testamento dexo declarado en la quinta cláusula de él cómo don Andrés Talaya, médico, me estaua deuiendo ducientos reales del alquiler de vna casa que está en la calle de la Cruz, perteneçiente a las Memorias que fundó Diego Ruiz Angelo, cuya cantidad se me pagó y dio satisfazión por los testamentarios del dicho don Andrés Talaya». Firma: «D. Manuel de Porras».

«Pinturas mandadas

a San Phelipe Neri

de Alcalá» Asimismo dejo declarado en dicho mi testamento que entre los vienes que dexo a la Congregación de San Phelipe Neri de la ciudad de Alcalá son diferentes pinturas, reliquias y escaparates que se allarán en mi casa al tiempo de mi fallecimiento y éstas se ponga [sic] en dicha Cassa de Alcalá, por quanto tengo bastantes esperiencias de lo que en estos casos suele suceder en las personas que no entienden el primor del Arte, de que llaman quien lo entienda para que lo tasse y los tales tasadores, como lleban la mira a comprarlo, tasan estas cosas en precios ynfimos y demás de ello quieren que les agan baxa, y consiguen llebarse en quatro lo que bale ciento y que el testamentario o eredero que lo benden no sauen si lo pagan bien o no por no entenderlo y redunda en menoscauo de los vienes. Y así este es el motibo que tengo para dejar estos vienes a la dicha Congregación de San Phelipe Neri de la ciudad de Alcalá de Henares, con calidad y condición de que ayan de serbir precisa y necesariamente en la Cassa de dicha Congregación de San Phelipe Neri que se está tratando de labrar en dicha ciudad de Alcalá. Y que la dicha Cassa y Padres de ella no an de poder bender ni enajenar dichas alajas por ninguna manera, causa ni pretesto sino es que las an de tener permanentes y que sirban en dicha yglesia para su adorno, especial y señaladamente tres escaparates: vno donde está Nuestra Señora con el Niño Jesús, San Juan y ángeles y un país, todo de bulto = Otro de San Eustaquio, que se le apareze un Christo sobre la cabeza de vn cierbo = Otro en vna vrna de concha de tortuga con el Nacimiento del Hixo de Dios = Vn óbalo que tiene vn retrato de bulto con su pie de ébano y marfil. Y todos de bulto con bidrieras christalinas $=$ Dos Niños de bulto, encarnados, de una tercia de alto $=$ Dos relicarios en forma de espejos con bidrieras christalinas con diferentes reliquias de Santos Apóstoles, Nuestra Señora y San Joseph, de tercia de alto, y vn biril de bronze con vn güeso de vna de las Onze Mill Bírgenes = Vna pintura de San Sevastián que le están atando, de bara y tercia de alto = Otra pintura de la Virgen, el Niño Jesús y San Joseph, de figuras de tamaño del natural = Otra pintura de bara de alto de La hija del Rey Faraón quando alló a Moysés en un zestillo de minbres por el rio = Otra pintura del mismo tamaño de San Merejildo sobre vn tablado y mucha gente = Otra pintura de dos baras de ancho y bara y quarta de alto de Nuestro Señor y los Apóstoles y el centurión con soldados armados = Otra pintura de media bara de alto de Nuestra Señora, el Niño Jesús, San Joseph y San Juan = Otra algo mayor de Nuestra Señora con el Niño Jesús en los brazos = Otra pintura de media bara de alto de Nuestra Señora de la Concepción yncada de rodillas rodeada de muchos ángeles = Otra pintura de tres quartas de ancho en un país con diferentes figuras que están en un festexo, que se llama bacanaria, con tres muchachos en el ayre tirando flechas = Otra pintura de tres quartas de alto de vna muger mirándose a vn espejo que le tiene vn muchacho = Vna Europa de tres quartas de ancho, poco más, sentada sobre vn toro, en el mar, con vnos muchachos en el ayre tirando flechas, con moldura parda. Otra pintura de tres quartas poco menos Ystoria del baño de Diana y con Anteón, con vnos perros y otras figuras bañándose = Otra pintura de tres quartas de alto y media bara de ancho de vna caueza de San Pedro, de mano de Juan Carreño = Otra pintura del mismo tamaño de vna caueza, retrato, con un sonbrero puesto, de mano de don Joseph Antolínez = Otra pintura de poco más de quarta de vna caueza de vna muger puesta a medio perfil, de mano de Matheo Carreño [sic] echa por su muger = Otra pintura de media bara en quadro de un país que es vn mar con un muchacho sentado en un delfín y unas sierras en lejos con más gente $=$ Otro país de media bara de ancho y una quarta de alto, con vna fuente enmedio, en que tiene por remate un muchacho echando agua por vna basija = Otras dos pinturas paises, de más de quarta de alto cada vna: en la una vn ángel cojiendo guindas de vn árbol, y el otro sin figuras y terazos. Otra pintura como de media bara de alto, con vn muchacho abrazado con vn perro. Todas de mano de autores grandes y con molduras negras, menos la Europa que es parda = Otras dos pinturas en óbalos, de dos o tres dedos de alto, pegado a unas molduras, retratos de mugeres, y el uno de Doña Ysabel de Borbón, que se allarán en vn escritorio $=$ Todas las dichas pinturas, reliquias y escaparates aquí mencionadas, se ayan de entregar luego que yo fallezca a los Padres trenitarios de descalzos de esta Corte para que las tengan en su Combento por bia de depósito asta tanto que la yglesia del dicho Combento de San Phelipe Neri de la ciudad de Alcalá esté acauada de azer en toda perfezión, para que allí puedan serbir y no antes, si no es que en el ynterin que durare dicho depósito sirban en la Capilla de Jesús Nazareno, sita en dicho Conbento de trinitarios, sin que dichos Padres trinitarios puedan benderlas ni entregarlas asta el dicho tiempo referido de auerse acauado la Yglesia. Y llegado el casso de que se entreguen dichas pinturas, reliquias y escaparates a los dichos Clérigos Menores de San Phelipe Neri de Alcalá por auerse perfecionado la yglesia, hayan los Padres trenitarios de ser lejisladores de los Clérigos de San Phelipe Neri de dicha ciudad de Alcalá, para que dichas pinturas y demás se coloquen en altares

AEA, LXXVI, 2003, 303, pp. 235 a 248 
y otras partes de dicha iglesia, sin que las puedan bender ni enaxenar dichos Padres de San Phelipe Neri. Y si lo contrario ycieren o yntentaren, hayan de poder pedir quenta de ellas los dichos Padres trenitarios y sacarlas de su poder y tomárselas en propiedad para su Combento de trenitarios, porque mi ánimo es que siempre ayan de permanezer y estar en ser para el adorno de la Yglesia en qualquiera de dichos dos Combentos, sin poderse bender ni enagenar, como lleuo dicho, y que sirba cada Combento, el vno de el otro, por fiscal y lexislador. Y que no an de poder prestarlas a persona alguna ni a pintores para que las copien, por el riesgo que tienen de que las maltratan y suelen trocar o quedar con ellas y echarlas a perder con los papeles aceitosos y colores que ponen enzima de los orixinales, y al limpiarlo con la miga de pan quitan el balor y la grasilla que tiene la pintura, quitándole el balor por este camino. Y para que se cumpla con mi boluntad, se entregarán dichas pinturas, reliquias y escaparates que ban espresadas a dicho Combento de trenitarios de descalzos y Padres de él, por quien se a de otorgar depósito de ellos en forma, con la obligación de tenerlo en su poder, como ba dicho, asta tanto de auerse acauado de labrar la yglesia de San Phelipe Neri de la ciudad de Alcalá, ante escribano y en forma. Y la misma obligazión an de tener los dichos Padres de San Phelipe de hacer y otorgar ante escribano, al tiempo que se les aga el entrego de dichas pinturas, de que las tendrán en su poder y pondrán en dicho Combento, como ba dicho». Firma: «D. Manuel de Porras».

Ordenó que se le diese «a doña María García, biuda, que bibe en el quarto segundo, en la misma casa que yo bibo al presente en las Quatro Calles, propia de don Joseph Martínez de Robles», doscientos rs. «en considerazión de lo que me a asistido en mi enfermedad». Firma.

«Manda al Combento de trenitarios. Es mi boluntad que luego que yo fallezca, se den y entreguen al Combento de trenitarios descalzos de esta Corte, quatro libros grandes, o los que fueren, y los demás libros en que estubieren pegados, de dibujos de mano de ynsignes pintores antiguos y modernos y de otros diferentes artífizes $=\mathrm{Y}$ asismismo otros diferentes libros, tanbién de dibujos, los quales no están pegados en las ojas blancas sino metidos entre oja y oja, y otros diferentes atados metidos entre pargaminos, y otros que están con bidrieras y molduras, y otros en bastidores y molduras, sin bidrieras $=\mathrm{Y}$ asimismo todo género de dibujos que se allaren en mi poder, ya sea de pluma y de lápiz o aguadas, los quales balen y me an costado muchísimos ducados y ser alajas muy esquisitas que e adquirido y conprado en el distrito de muchos años. Por cuya razón, es mi boluntad que todos los dichos libros y demás, los dichos Padres trinitarios los coloquen y pongan en la Librería grande que tienen en dicho Conbento, en la que ay escomunión para no sacar de ella cosa alguna, para que tenga esta grandeza demás dicha Librería y no se puedan sacar de la puerta afuera estas cosas, y por el riesgo que tiene de que se estrabien algunos y los vrten, porque estas cosas son de mucha golosina para artífizes y pintores, que yo los e juntado por la grande afizión que e tenido a este género de cosas y e gastado mucha hazienda. Y quiero que no se bendan a ninguna persona ni se menosprezien, por las grandes esperienzias que tengo de conprar estas cosas los mesmos que las an tasado en precios muy cortos por llebar la mira de comprarlos. Y así es mi boluntad que no los puedan bender los dichos Padres trenitarios, en público ni en secreto, sino es que queden permanentes en dicha Librería. Y que queden con el grauamen y sujetos a que si los bendiesen o enagenasen, puedan pedírselos los Padres de San Phelipe Neri de la Cassa que al presente tienen en la ciudad de Alcalá y se enpieza a labrar yglesia nueba. Y para que se cumpla con mi boluntad, se entregarán por mis testamentarios a los Prelados de dicho Combento de trinitarios, tomando carta de pago de ello ante escribano y en forma, otorgada por dichos Prelados y Difinidores, y obligándose a tenerlos en dicha Librería perpetuamente, como ba referido. Y que dichos Padres trinitarios cosan y agan libros, según los tamaños, para que no anden sueltos dichos papeles de dibujos y estanpas, así éstas como las demás que llebaré mandadas en adelante a dicho Combento». Firma.

«Yden. Asimismo es mi boluntad que luego que yo fallezca, se les dé y entregue a dichos Padres trinitarios de descalzos de esta Uilla diferentes cantidades de enboltorios atados y libros y rollos de estanpas de papel, vnas forradas en lienzo y otras sin forrar, las quales tengo y paran en mi poder, que son mias propias, que tanbién balen y me an costado muchos ducados, por ser de gran balor y estimazión y de autores de diferentes naçiones y Escuelas, como es de Benecia, Flandes, Françia y otras partes. Lo qual an de colocar asimismo y poner en dicha Librería donde no se pueda sacar ni bender ni dar. Y si lo ycieren, puedan quedar sujetas y con el grauamen de poder pedirlas y sacarlas de poder de quien los tubiere la dicha Congregación de San Phelipe Neri de la ciudad de Alcalá, así lo que ba espresado y lleuo mandado asta aquí a dicho Combento de trenitarios descalzos de esta Corte, como ba dicho, como lo que se ará menzión y le mandaré en adelante, sin reseruazión de cosa alguna $=\mathrm{Y}$ asimismo se les dé y entregue a dichos Padres trinitarios de descalzos de esta Corte tres figuras de bulto: la vna de vn ladiator [sic], de media bara de alto, firmada en lengua griega del autor Glayzo; y las otras dos figuras de una quarta de alto cada una, con sus peanas: la una de bronze, que hace vn mobimiento que carga la cabeza contra el pecho, y la otra es de metal, en pie, llamada el Antiño [sic]. Y se adbierte que entre los libros que tengo de leyenda, ay otros libros de estanpas de papel. Y es mi boluntad que tanbién se den y entreguen dichos libros de estanpas a dichos Padres trenitarios de descalzos. Y dichas estatuas, con el mismo grauamen que lo demás que lleuo mandado, para que estén y los pongan en dicha Librería grande». Firma.

«Yden. Digo que yo conpré de don Francisco Martínez, que al presente asiste y bibe en la calle de los Preçiados, en cassa del Marqués Ayroldo, estrangero, siete estanpas de papel forradas en lienzo, de cosa de 
bara y media de largo las zinco, y las dos algo más pequeñas; que las cinco de ellas son de la Ystoria y azañas del Enperador Alexandro Magno, y las otras dos de las Azañas de el Enperador Constantino Magno, en precio de diez y ocho doblones de a dos escudos de oro; los quales están arollados y atados en un cofre que se allará en el aposento donde duerme mi criada. Es mi boluntad que dichas estanpas y otras estanpas y dibujos que ay en dicho cofre también se les dé y entreguen a dichos Padres trinitarios descalzos para que asimismo los pongan en dicha Librería con las demás cosas, por ser éstas de mucho balor y estimazión, y que por ningún aconteçimiento, causa ni motibo se buelban a bender ni enagenar a persona alguna ni al mesmo que me las bendió, si no es que las conserben perpetuamente como todo lo demás que lleuo mandado y con el propio grauamen que refiero en dichas cláusulas y que les puedan pedir quenta y quitárselas los Clérigos de San Phelipe Neri de la dicha ciudad de Alcalá si lo contrario yçieren. Y que los motibos que tengo para dejar estas cosas con dichos grauámenes y circunstanzias son diferentes y no los espreso.

$\mathrm{Y}$ porque mi ánimo hes que no se aga almoneda de estos vienes ni de otros, en mi casa ni fuera de ella, por las esperiencias que tengo de los fraudes que se an cometido y menoscauo del balor que an tenido las alajas que se an bendido en diferentes almonedas y mayormente estos géneros de cosas que son codiciosas para artífizes y éstas las tasan en precios ynfimos con el ánimo de conprarlas muy baratas, siendo así que, como llebo dicho, me an costado cantidades muy excesibas de doblones y reales de a ocho $=\mathrm{Y}$ se advierte que todo lo que mira, así a dibujos de mano de autores grandes como de estanpas ynpresas en papel, enquadernados como sueltos, estanpas y dibujos y las estatuas que ban referidas, lo dejo y mando en propiedad para sienpre jamás y desde luego con el grabamen dicho de que no puedan benderlo ni enagenarlo, sino que lo ayan de poner en la Librería grande, donde está la escomunión reserbada del Pontífize, donde no pueden sacar libro ni alaja ninguna de la puerta afuera, ni los puedan dar ni prestar a persona alguna ni a pintores para que los copien, por el riesgo que tienen de trocarlos y echar a perder y maltratarlos o quedar con ellos = Y lo que mira a pinturas, éstas las an de tener los dichos Padres trinitarios en su Conbento por bia de depósito, como ba referido, asta tanto de hauerse acauado la iglesia de dichos Clérigos Menores de San Phelipe Neri de la ciudad de Alcalá = Y se adbierte que lo que mira a libros impresos de leyenda y manuescritos orixinales que se allarán en mi casa, éstos no ban compreendidos en depósito ni en manda, si no es que ayan de quedar y quedan para que los perciba y goze desde luego la Casa de San Phelipe Neri de la ciudad de Alcalá, a quien dejo por mi heredero». Firma.

Mandó que, después de su fallecimiento, se diesen cincuenta rs. vn. a los trinitarios descalzos para que dijesen cincuenta misas rezadas de réquiem por las ánimas del Purgatorio y las de sus padres y parientes. Firma.

Que se diesen a doña María García cincuenta reales más. Firma.

Otros cincuenta rs. a Esteban Angulo, mercader de lonja, que vivía frente a la torre de la iglesia parroquial de Santa Cruz.

Que se pagase lo que se le debía a José de Guardaminos, escribano y se le diesen ochenta rs. más por haberle ayudado a hacer la memoria.

Declaró que había cobrado mil trescientos veinte rs. que pertenecían a doña María Teresa Vázquez Coronado, religiosa en el Convento de Santi Spiritu de la Orden de Santiago de Salamanca, por la renta que le estaba consignada en un efecto sobre la sisa del vino.

«Y asta aquí e continuado con esta memoria que ba escrita en nuebe foxas con ésta, y quiero y es mi boluntad se tenga por la misma que dejo referida en el dicho mi testamento, y se guarde y cumpla y execute como parte de él, como si partida por partida en él estubiera ynclusa. Y si se me ofreciere otra cosa, lo pondré por memoria a continuación de ésta. Y lo firmé en la Uilla de Madrid, a veinte y uno de septiembre de mill seiscientos y nobenta y nuebe años $=$ enmendado =mes=». Firma: «D. Manuel de Porras». Madrid, 21IX-1699. (AHP: Protocolo 14276, fols. 740-747).

\section{Documento n. ${ }^{\circ}$ 4:}

El Cura de la iglesia parroquial de Santa Cruz bautizó a «Dionisio, hijo de Julián de Paredes y de doña Maria Hidalgo, su lejítima mujer, que viuen en la plaçuela del Anjel, casas de doña Juana Suárez. Fue su padrino Juan Hidalgo..., siendo testigos Juan de Lope, Christoual Díaz...». (LBSC, 16-V-1662). 